\title{
Stability of hydrogen peroxide during perhydrolysis of carboxylic acids on acidic heterogeneous catalysts
}

Sébastien Leveneura,b*, Narendra Kumar a, Tapio Salmia , Dmitry Yu. Murzina aLaboratory of Industrial Chemistry and Reaction Engineering, Process Chemistry Centre, Åbo Akademi University, Biskopsgatan 8, Fl-20500 Åbo/Turku, Finland. Tel: +358 2215 8942; Fax: +358 2215 4479; E-mail: sleveneu@abo.fi bLSPC-Laboratoire de Sécurité des Procédés Chimiques, INSA Rouen, Place Emile Blondel, BP8, 76131 Mont-Saint-Aignan Cedex, France.

\section{ABSTRACT}

This paper describes a study of the stability of hydrogen peroxide in the presence of different aluminosilicate materials, in connection with investigation of carboxylic acid perhydrolysis. During the reaction, aluminosilicate materials such as $\mathrm{H}-\beta$ zeolites, mesoporous material $\mathrm{H}-\mathrm{MCM}-41$ and alumina initiate the decomposition of hydrogen peroxide. The reason of the spontaneous decomposition of $\mathrm{H}_{2} \mathrm{O}_{2}$ is related to the partial dealumination of these zeolites. However, in case of experiments carried out with $\mathrm{H}-\mathrm{ZSM}-5$ zeolite catalysts, a slight catalytic effect on the perhydrolysis and no spontaneous decomposition of hydrogen peroxide were noticed. The use of cation exchange resins as catalysts is more kinetically beneficial than H-ZSM-5 zeolite catalysts.

Keywords: perhydrolysis; aluminosilicate materials; decomposition; hydrogen peroxide 


\section{Introduction}

The interest in hydrogen peroxide has increased in the last decade. For instance, the world production of hydrogen peroxide was around 1.9 million tonnes in 1994, and grew to 2.2 million tonnes in 2006 [1]. The applications of this compound are versatile: it is used as an oxidizing agent for inorganic and organic compounds, bleaching agent for textiles and wood, as an antiseptic for therapeutic use, as a disinfectant for wastewater and as a sterilizing agent.

The use of $\mathrm{H}_{2} \mathrm{O}_{2}$ as an oxidizing agent [2] in chemistry avoids the use of conventional heavy-metal oxidants which form toxic waste; application of nitric acid which form the greenhouse gas $\mathrm{N}_{2} \mathrm{O}$; and utilization of molecular oxygen, which requires safety precautions. Scheme 1 illustrates the application of hydrogen peroxide in some fine chemical synthesis reactions [3].

\section{Scheme 1. Applications of $\mathrm{H}_{2} \mathrm{O}_{2}$ in fine chemical reactions}

From environmental and economical point of view, these reactions should be carried out with heterogeneous catalysts, which should not decompose hydrogen peroxide. 
The aim of this paper is to treat the stability issues of $\mathrm{H}_{2} \mathrm{O}_{2}$ in acidic environment over different heterogeneous catalysts, and especially aluminosilicate materials. Traditionally, synthetic aluminosilicate materials, and more particularly synthetic zeolites are widely used as catalysts in the petrochemical industry, for instance in fluid catalytic cracking and hydro-cracking. The use of zeolites for fine chemicals production is widespread: acylation, alkylation, hydroxyalkylation of aromatic and heterocyclic compounds and rearrangement reactions [4]. Selectivity (including shape selectivity), catalytic effects and environmental regulations explain the application of such materials in industry. In particular, oxidation reactions such as epoxidation of olefins, hydroxylation of arenes, oxidation of $\mathrm{O}-, \mathrm{S}-$ and $\mathrm{N}$ - functionalities with hydrogen peroxide are conducted using Ti-zeolites. The originality of this paper is the investigation of an oxidation reaction with $\mathrm{H}_{2} \mathrm{O}_{2}$ in the presence of titanium free aluminosilicate materials.

To illustrate the stability of $\mathrm{H}_{2} \mathrm{O}_{2}$, the peroxycarboxylic acids synthesis was selected as a model reaction (Scheme 2).

\section{Scheme 2. Synthesis of PCA from the parent carboxylic acid and hydrogen peroxide}

This reaction occurs at acidic $\mathrm{pH}$ [5-7], and is traditionally catalyzed by sulfuric acid. This reaction was selected because spontaneous decomposition of hydrogen peroxide or peroxycarboxylic acids is negligible [8-10] in traditional experimental 
conditions ( $\mathrm{pH}: 1-3$; and temperature: $\left.20-50^{\circ} \mathrm{C}\right)$; and configurational diffusion can be neglected because the size of the reactant molecules is smaller compared to the pore size of the materials used (Table 1). Thus, by using heterogeneous catalysts for this reaction, only decomposition due to the solid acid catalyst can occur.

Table 1. Channel structure of the tested aluminosilicate materials

In a previous paper, we have demonstrated that cation-exchange resins [11] are suitable heterogeneous catalysts for the carboxylic acids perhydrolysis. Our objective in the present study is to elucidate hydrogen peroxide stability towards aluminosilicate type materials, and to compare the catalytic efficiency of these aluminosilicate materials versus cation-exchange resins in such reactions.

Except the communication of Palani et al. [12], in which the efficacy of different zeolites and mesoporous materials was investigated, there are no other scientific papers dealing with perhydrolysis of carboxylic acids over these materials. 


\section{Experimental section}

\subsection{Apparatus and experimental procedures}

All experiments were performed in a $250 \mathrm{ml}$ jacketed glass reactor vessel. The reactor was equipped with a mechanical agitator and a temperature probe. Water was pumped through the outer jacket of the vessel to control the temperature of the reaction mixture. A pitched blade impeller (PTFE coated) was used to ensure a vigorous mixing during the reaction.

A reflux condenser was attached to the top of the reactor (adjusted at $0^{\circ} \mathrm{C}$ ) to avoid loss of volatile liquid-phase compounds. In case that decomposition of peroxypropionic acid (PPA) or $\mathrm{H}_{2} \mathrm{O}_{2}$ appeared, an inert carrier gas (Helium, AGA, 99.996\%) was introduced to the reactor through one of the necks to avoid the accumulation of oxygen in the gas phase.

To prevent contamination induced by alkaline and metal components, which initiate the catalytic decomposition of peroxypropionic acid and hydrogen peroxide, all parts of the reactor system being in contact with the reaction solution were washed with hydrochloric acid followed by another washing, with a phosphate-free detergent solution. 
In case of experiments carried out for testing the stability of hydrogen peroxide towards zeolite, at first stage, deionized water and zeolites were mixed together in the reactor. As the desired reaction temperature was reached, the preheated hydrogen peroxide solution (Merck, 30 wt.\%) was added through a dropping funnel. In fact, hydrogen peroxide was preheated at the same temperature as the reaction temperature. At the time "zero" the required amount was introduced into the reactor.

In case of experiments carried out for checking the catalytic effect of zeolites on the propionic acid perhydrolysis reaction, at the first stage, propionic acid (Acros, 99 wt.\%) and the catalyst were mixed together in the reactor. Thereafter, the same protocol as described above was followed.

According to a patent [13], during the reaction of hydrogen peroxide and propionic acid in water in presence of an acid catalyst, the danger of explosion is suppressed by employing a temperature of maximum $60^{\circ} \mathrm{C}$.

From our previous study $[9,11]$, the kinetics of propionic acid perhydrolysis is demonstrated to be dependant on the Brønsted acid sites in case of homogeneous and heterogeneous catalysis. One should keep in mind that the goal is to check the stability of hydrogen peroxide towards aluminosilicate materials in acidic environment by study the reaction of perhydrolysis. Due to the low Brønsted acid site amount of these catalysts and the difficulty to measure them in the temperature range $40-50^{\circ} \mathrm{C}$, the kinetic comparisons were based on catalyst loading. Table 2 introduces the experimental matrix. 
Table 2. Experimental parameters for the catalyst comparison in the batch reactor

\subsection{Analytical methods}

Samples were withdrawn from the reaction mixture by a plastic syringe (to avoid contamination of the solution by trace of metals) and they were analyzed by the Greenspan and Mackellar method [14]. The concentration of hydrogen peroxide was determined by titration by using a standard solution of ammonium cerium sulphate $(0.1 \mathrm{~N})$. The concentrations of propionic and peroxypropionic acids were determined by titration with an automatic titrator (Metrohm 751 GPD Titrino) by using a standard solution of sodium hydroxide $(0.2 \mathrm{~N})$. 


\subsection{Catalyst properties}

The acidic properties of the different aluminosilicate materials are summarized in Table 3. The Brønsted and Lewis acid sites were determined by FTIR using pyridine as probe molecule [15-18]. The specific surface area was determined by $\mathrm{N}_{2}$ adsorption, calculated by Dubinin method for the microporous materials and by BET method for the mesoporous H-MCM-41 [15-18].

Table 3. Properties of the aluminosilicate materials

A comparison between a cation exchange resin, i.e., Amberlite IR-120 and zeolites was carried out. The characteristics of this commercial resin are summarized in Table 4.

Table 4. Properties of Amberlite IR-120

The pretreatment of Amberlite IR-120 consisted of a drying step at $70^{\circ} \mathrm{C}$ for $48 \mathrm{~h}$, since a higher drying temperature might affect the sulfonic acid sites on the catalyst. The parameter capacity by dry weight represents the number of Brønsted groups bearing (i.e., sulfonic group) by the resins, which is equivalent to the Brønsted acid sites of zeolites displayed in Table 3.

To dealuminate zeolite, the protocol of Marques et al. [19] was applied to H- $\beta-25$ zeolite, i.e., an acid treatment at $30^{\circ} \mathrm{C}$ by $\mathrm{HCl}(1 \mathrm{~N})$ for 10 min was performed. 
The $\mathrm{Al}$ concentration in the reaction mixture was measured by ICP-OES (PerkinElmer Optima 5300DV). 


\section{Results and discussion}

Experiments of the perhydrolysis of propionic acid over different aluminosilicate materials gave two antagonist observations: either the catalyst was active in perhydrolysis, or no formation of peroxypropionic acid was observed due to the decomposition of hydrogen peroxide over these acidic materials.

\subsection{Aluminosilicate materials initiating the decomposition of hydrogen peroxide}

During the reaction of perhydrolysis, decomposition of hydrogen peroxide was observed with the following materials: $\mathrm{H}-\beta$ zeolites, $\mathrm{H}-\mathrm{MCM}-41$ and alumina. For the

sake of simplicity, the ratio $\frac{\left[\mathrm{H}_{2} \mathrm{O}_{2}\right]}{\left[\mathrm{H}_{2} \mathrm{O}_{2}\right]_{0}}$, where $\left[\mathrm{H}_{2} \mathrm{O}_{2}\right]_{0}$ is the initial concentration, was plotted versus the reaction time. An experiment with only hydrogen peroxide without any catalyst was carried out at $50^{\circ} \mathrm{C}$; no spontaneous decomposition of this reactant was observed.

According to Sengupta et al. [20], the decomposition of hydrogen peroxide on unimpregnated silica-alumina material is dependent of the strength of acid sites. In our previous studies $[9,11]$ no decomposition of hydrogen peroxide was noticed due to Brønsted acidity in either sulfuric acid or sulfonic groups bearing by the resins. For that reason Lewis acid sites in such materials can be thought to be responsible for the decomposition of hydrogen peroxide. 
However, Rocha et al. [21] have studied the kinetics of peroxyacetic acid formation from acetic acid and hydrogen peroxide in the presence of scandium (III) triflate. They have demonstrated that the use of this strong Lewis acid enhanced the reaction rate six fold compared to the catalyst absence; and no decomposition of hydrogen peroxide was reported.

Several articles treat the dealumination of $\mathrm{H}-\beta$ zeolites [22-23], or type $A$ and $Y$ zeolites [24] by acidic leaching. Marques et al. [19] have shown that treatment of $\mathrm{HBEA}$ zeolite $(\mathrm{Si} / \mathrm{Al}=12.5)$ with an $\mathrm{HCl}$ solution at $30^{\circ} \mathrm{C}$ causes a rapid dissolution of the extraframework Al species, especially the monomeric ones and a slow dissolution of the framework $\mathrm{Al}$ atoms bridging $\mathrm{OH}$ groups and structure defects. These $\mathrm{Al}$ species released in the reaction mixture could catalyze the $\mathrm{H}_{2} \mathrm{O}_{2}$ decomposition.

In this chapter, the reason of hydrogen peroxide decomposition will be discussed regarding the Lewis acid, partial dealumination and $\mathrm{SiO}_{2} / \mathrm{Al}_{2} \mathrm{O}_{3}$ ratio.

Fig. 1 displays three different experiments carried out with $\mathrm{H}-\beta-25$ zeolites.

\section{Fig. 1 Experiments carried out in the presence of $\mathrm{H}-\beta-25$ zeolite at $50^{\circ} \mathrm{C}$, at 350 rpm and loading of $18.25 \mathrm{~g} / \mathrm{l}$}

The difference of $\mathrm{pH}$ is due to the presence of PA, which acidifies the mixture. In case of experiments carried out with a mixture PA and $\mathrm{H}_{2} \mathrm{O}_{2}$, concentration of PA remains constant. Even if the decomposition of $\mathrm{H}_{2} \mathrm{O}_{2}$ is strongly dependent on the $\mathrm{pH}$, 
one can conclude that the production of PPA or presence of PA does not influence the kinetic of decomposition. From Fig. 1, the kinetics of hydrogen peroxide decomposition for experiments carried out with $\mathrm{PA}$ and $\mathrm{H}_{2} \mathrm{O}_{2}$ mixture in presence of $\mathrm{H}-\beta-25$ and dealuminated $\mathrm{H}-\beta-25$ by acidic treatment is similar. This observation implies that the decomposition of hydrogen peroxide is due to Al species, in particular dissolution of $\mathrm{Al}$ atoms from the framework of the zeolite. The difference of aluminium concentration between the end and the beginning of the experiment carried out with $\mathrm{H}-\beta-25$ and $\mathrm{PA}$ and $\mathrm{H}_{2} \mathrm{O}_{2}$ mixture was measured to be equal to $181 \mathrm{mg}^{-1} \mathrm{I}^{-1}$, which can explain the decomposition of hydrogen peroxide.

From Fig. 1, one can notice the presence of an initial retarding period, which is more significant in case of the experiment carried out with $\mathrm{H}-\beta-25$ and $\mathrm{PA}$ and $\mathrm{H}_{2} \mathrm{O}_{2}$ mixture. The presence of the initial retarding effect, occurring for a long time period, during the decomposition of hydrogen peroxide is not the first observation in the literature. For instance, this phenomenon of retarding phase was noticed in case of $\mathrm{H}_{2} \mathrm{O}_{2}$ decomposition by $\mathrm{Fe}(\mathrm{III})$. De Laat et al. [25] had explained it by the formation of $\cdot \mathrm{OH}$ radicals via Fenton's reaction, with duration of this phase depending on various parameters, such as the initial concentration of $\mathrm{Fe}(\mathrm{III})$. In the present case, this retarding period could be explained by the dissolution of Al. Indeed, in case of experiments carried out over dealuminated $\mathrm{H}-\beta-25$ this retarding period seems to be shorter, because Al atoms from the extraframework have been already removed by acidic treatment. 
To check if the decomposition of hydrogen peroxide in such conditions is due to the partial dissolution of Al species in the liquid phase, an experiment with aluminium oxide was carried out (Fig. 2). Alumina was chosen instead of an aluminium salt because its structure is closer to Al species present in the zeolites.

Fig. 2 Experiment carried out with a mixture of $\mathrm{PA}$ and $\mathrm{H}_{2} \mathrm{O}_{2}$ over alumina at $50^{\circ} \mathrm{C}$, at $350 \mathrm{rpm}$ and loading of $18.25 \mathrm{~g} / \mathrm{l}$

Fig. 2 shows that hydrogen peroxide decomposes over $\mathrm{Al}_{2} \mathrm{O}_{3}$, which implies that the assumption of $\mathrm{H}_{2} \mathrm{O}_{2}$ decomposition is related to the partial dissolution of $\mathrm{Al}$ species is plausible. The ratio $[\mathrm{PA}] /[\mathrm{PA}] \mathrm{o}$ remained constant during this experiment.

To check if the decomposition of hydrogen peroxide is related to the ratio $\mathrm{SiO}_{2} / \mathrm{Al}_{2} \mathrm{O}_{3}, \mathrm{H}-\beta$ zeolites with three different $\mathrm{SiO}_{2} / \mathrm{Al}_{2} \mathrm{O}_{3}$ ratios were used as displayed by Fig. 3. No production of PPA was noticed, but instead, decomposition of hydrogen peroxide was observed.

Fig. 3 Experiments carried out with a mixture of $\mathrm{PA}$ and $\mathrm{H}_{2} \mathrm{O}_{2}$ over $\mathrm{H}-\beta$ zeolites at $50^{\circ} \mathrm{C}$, at $350 \mathrm{rpm}$ and loading of $18.25 \mathrm{~g} / \mathrm{l}$

During these experiments, the concentration of PA remained constant (Fig. 3). The kinetic curves are similar, but there is an initial retarding effect during the experiments 
carried out with $\mathrm{H}-\beta-75$ and $\mathrm{H}-\beta-25$. No decomposition of hydrogen peroxide was reported in the paper of Palani et al. [12] during the synthesis of peroxyacetic acid using $\mathrm{H}-\beta$ with a ratio Si/Al equal to 12 , catalyst loading lower than $1 \mathrm{~g} / \mathrm{l}$ and at $25^{\circ} \mathrm{C}$. From Fig. 3, it can be concluded that the decomposition is not directly related to the $\mathrm{SiO}_{2} / \mathrm{Al}_{2} \mathrm{O}_{3}$ ratio.

Although, the amount of Lewis acid sites is 5 times higher in case of $\mathrm{H}-\beta-25$ than $\mathrm{H}-\beta$ 75 or $\mathrm{H}-\beta-300$ (Table 3), the kinetics of decomposition is similar. Thus, the Lewis acid sites bearing on these materials are not responsible for the $\mathrm{H}_{2} \mathrm{O}_{2}$ decomposition. Furthermore, the amount of Lewis acid sites in $\mathrm{H}-\mathrm{ZSM}-5-23$, which does not induce the decomposition of $\mathrm{H}_{2} \mathrm{O}_{2}$, is on the same order of magnitude as in $\mathrm{H}-\beta-75, \mathrm{H}-\beta-300$ or H-MCM-41 (Table 3). Thus, the assumption that the decomposition of hydrogen peroxide is due to the presence of Lewis acid sites in aluminosilicate materials can be rejected.

During the experiments, the decomposition of $\mathrm{H}_{2} \mathrm{O}_{2}$ appeared only at zeolite loadings exceeding $8.26 \mathrm{~g} / \mathrm{l}$, which explains the absence of decomposition in the study of Palani et al. [12]. Below this catalyst loading, the perhydrolysis of propionic acid due to the protolysis of the carboxylic acids occurs [7]. The change of the catalyst loading in the range 10.24-18.25 $\mathrm{g} / \mathrm{l}$ does not influence the kinetics of $\mathrm{H}_{2} \mathrm{O}_{2}$ decomposition at $50^{\circ} \mathrm{C}$ (Fig. 4). In both cases, there is a retarding effect; however, this induction period is longer for the experiment carried out with a loading of 18.25 $\mathrm{g} / \mathrm{l}$. 


\section{Fig. 4 Experiments carried out with a mixture of $\mathrm{PA}$ and $\mathrm{H}_{2} \mathrm{O}_{2}$ over $\mathrm{H}-\beta-75$ zeolites at $50^{\circ} \mathrm{C}$ and at $350 \mathrm{rpm}$}

A mesoporous material $\mathrm{H}-\mathrm{MCM}-41$ was used to study its behaviour in the mixture of PA and $\mathrm{H}_{2} \mathrm{O}_{2}$. Fig. 5 displays the kinetics of $\mathrm{H}_{2} \mathrm{O}_{2}$ decomposition versus time for this mixture over $\mathrm{H}-\mathrm{MCM}-41$ and $\mathrm{H}-\beta-75$ at $40^{\circ} \mathrm{C}$. During these reactions, the concentration of PA remains constant. From Fig. 5 one can notice the same trend as with alumina or $\mathrm{H}-\beta$ materials, i.e., a decomposition phase of hydrogen peroxide. The retarding period is more pronounced at the beginning of the reaction (until $300 \mathrm{~min}$ ) for $\mathrm{H}-\mathrm{MCM}-41$ than for $\mathrm{H}-\beta-75$, which can be explained by the higher stability of the mesoporous material towards on acidic environment. After the induction period, the kinetics of $\mathrm{H}_{2} \mathrm{O}_{2}$ decomposition is similar in both cases.

\section{Fig. 5 Experiments carried out with a mixture of PA and H2O2 over H-MCM-41 and $\mathrm{H}-\beta-75$ at $40^{\circ} \mathrm{C}$ and at $350 \mathrm{rpm}$}

The decomposition of hydrogen peroxide is due to the presence of Al species dissolved from the framework structure of the $\mathrm{H}-\beta$ zeolites and mesoporous materials $\mathrm{H}-\mathrm{MCM}-41$. The slow kinetics of $\mathrm{H}_{2} \mathrm{O}_{2}$ is related to the fact that the dissolution of $\mathrm{Al}$ species from the framework is a slow phenomenon [19]. Furthermore, the Al species released are in oxide or hydroxide form, and according to Mani et al. [26], their catalytic activity towards hydrogen peroxide decomposition is minor. 


\subsection{Materials which catalyze the perhydrolysis reaction}

In case of experiments carried out with H-ZSM-5 or Amberlite IR-120, no decomposition of hydrogen peroxide was noticed, while the catalytic effect on the perhydrolysis of propionic acid was visible. The purpose of this section is to propose an explanation for the selectivity of the aluminosilicate materials towards the reaction between $\mathrm{H}_{2} \mathrm{O}_{2}$ and $\mathrm{PA}$, and to perform a comparative study of these materials. This comparison was based on equal catalyst loadings, and the experiments were carried out under similar conditions.

Fig. 6 shows that H-ZSM-5 zeolite catalyzes the perhydrolysis of propionic acid. Moreover, the activity of H-ZSM-5-23 is higher than H-ZSM-5-31, due to higher amount of Brønsted acid sites. In case that no external catalyst is added, some perhydrolysis takes place (Fig. 6). This is due to the fact that propionic acid itself is a weak Brønsted acid having some catalytic effect.

\section{Fig. 6 Formation of PPA over different catalysts at $50^{\circ} \mathrm{C}$ at $43.38 \mathrm{~g} / \mathrm{l}$ of loading and $350 \mathrm{rpm}$}

Fig. 6 demonstrates that cation exchange resins are more beneficial than zeolites for the synthesis of peroxypropionic acid from hydrogen peroxide and propionic acid. An estimation of the apparent second-order rate constants based on the product $[P A]^{*}\left[\mathrm{H}_{2} \mathrm{O}_{2}\right]$ is provided in Table 5. The apparent Brønsted acid concentration $\left[\mathrm{H}^{+}\right]$is also displayed for each catalyst (except for H-ZM5-31), which is the sum of the 
amount of Brønsted acid sites of the solid catalyst and the number of hydroxonium ions released due to the protolysis of PA present per litre of reaction mixture.

Table 5. Apparent rate constants and $\left[\mathrm{H}^{+}\right]$

\section{Fig. 7 Rate constants versus apparent $\left[\mathrm{H}^{+}\right]$}

Fig. 7 displays the rate constants versus the apparent Brønsted acid concentration $\left[\mathrm{H}^{+}\right]$for each catalyst. As can be seen the apparent rate constants are linearly proportional to $\left[\mathrm{H}^{+}\right]$, which confirms the fact that the reaction of perhydrolysis is catalyzed by the Brønsted acid sites. Amberlite IR-120 catalyzes 4 times faster the perhydrolysis of PA than $\mathrm{H}-\mathrm{ZSM}-5-23$, for this reason cation exchange resins are preferred in practice.

According to Lutz et al. [27], the dense-structured zeolites of types ZSM-5 (MFI) are relatively stable under treatment by liquid water for $72 \mathrm{~h}$ up to $513 \mathrm{~K}$; whereas, the open-structured zeolites of type beta (BEA) undergo strong decomposition in the same range. This statement shows that $\mathrm{H}-\beta$ zeolites are more fragile than $\mathrm{H}-\mathrm{ZSM}-5$ zeolites regarding the dealumination. In other words the dissolution of Al species is easier in the case of $\mathrm{H}-\beta$ zeolites than $\mathrm{H}-\mathrm{ZSM}-5$ zeolites. 
More generally, material with a MFI structure seems to be preferably used in case of oxidation by hydrogen peroxide. For instance, titanium silicate zeolite TS-1, which has a MFI structure, is a material specifically designed for industrial oxidation reaction with hydrogen peroxide [28].

\section{Conclusions}

This paper describes a study of hydrogen peroxide stability over different aluminosilicate materials in the perhydrolysis of propionic acid. Several experiments were carried out in an isothermal batch reactor at temperatures $40-50^{\circ} \mathrm{C}$, equimolar concentrations of the reactants and with hydrogen peroxide alone.

It was observed that some aluminosilicate materials (as $\mathrm{H}-\beta, \mathrm{H}-\mathrm{MCM}-41$ or alumina oxide) decompose hydrogen peroxide, but other one (as H-ZSM-5) catalyze the perhydrolysis reaction in a moderate way.

Experiments carried out with $\mathrm{H}-\beta$ zeolites showed that the decomposition of hydrogen peroxide is not directly proportional to the ratio $\mathrm{SiO}_{2} / \mathrm{Al}_{2} \mathrm{O}_{3}$ or to the Lewis acid site bearing by these materials. But it appears that the decomposition of hydrogen peroxide over these catalysts is related to the partial dealumination of the zeolites framework, releasing Al species in the midst which induce the decomposition mechanism. This assumption was supported by literature data, and the observation that alumina oxide material decomposes hydrogen peroxide during the propionic acid 
perhydrolysis reaction. A certain minimal amount of material (ca. $8.26 \mathrm{~g} / \mathrm{l})$ is needed to initiate the decomposition. The change of catalyst loading in the range 10.24-18.25 $\mathrm{g} / \mathrm{l}$ does not change the kinetics of $\mathrm{H}_{2} \mathrm{O}_{2}$ decomposition.

The retarding period preceding the $\mathrm{H}_{2} \mathrm{O}_{2}$ decomposition is connected to the partial dealumination period of the zeolites. The duration of this period depends on several parameters such as: $\mathrm{pH}$ of the solution, catalyst loading and nature of the zeolite structure.

$\mathrm{H}-\mathrm{ZSM}-5$ does not decompose hydrogen peroxide, and in the case of a high number of Brønsted acid sites a catalytic effect on the perhydrolysis of propionic acid is observed. Amberlite IR-120 was, however even more beneficial by 4 times compared to H-ZSM-5-23. 


\section{ACKNOWLEDGEMENT}

The financial support from the Åbo Akademi Forskningsinstitut and the Finnish Graduate School in Chemical Engineering (GSCE) are gratefully acknowledged. This

work is part of activities at the Åbo Akademi Process Chemistry Centre (PCC) within the Finnish Centre of Excellence Programme (2006-2011) by the Academy of Finland. 


\section{REFERENCES}

1. R. Hage, A. Lienke, Angew. Chem. Int. Ed. 45, 206 (2006).

2. R. Noyori, Chem.Commun. 14, 1807 (2005).

3. C.W. Jones, Application of Hydrogen Peroxide and Derivatives, $1^{\text {st }}$ edn. (Royal Society of Chemistry, Cambridge, 1999), pp. 49-53

4. M.G. Clerici, Top. Catal. 13, 373 (2000).

5. L. V. Dul'neva, A.V. Moskvin, Russ. J. Gen. Chem. 75, 1125 (2005).

6. X. Zhao, T. Zhang, Y. Zhou, D. Liu, J. Mol. Catal. A: Chemical 271, 246 (2007).

7. S. Leveneur, T. Salmi, D. Yu. Murzin, L. Estel, J. Wärnå, N. Musakka, Ind. Eng. Chem. Res. 47, 656 (2008).

8. N. Musakka, T. Salmi, J. Wärnå, J. Ahlkvist, M. Piironen, Chem. Eng. Sci. 61, $6918(2006)$.

9. S. Leveneur, T. Salmi, N. Musakka, J. Wärnå, Chem. Eng. Sci. 62, 5007 (2007).

10.X. Zhao, K. Cheng, J. Hao, D. Liu, J. Mol. Catal. A: Chemical 284, 58 (2008).

11.S. Leveneur, D. Yu. Murzin., T. Salmi, J.-P. Mikkola, N. Kumar, K. Eränen, L. Estel, Chem. Eng. J. 147, 323 (2009).

12. A. Palani, A. Pandurangan, Catal. Commun. 7, 875 (2006).

13. G. Prescher, O. Weiberg, H. Waldmann, H. Seifert, International Patent US4088679 (1978).

14. F.P. Greenspan, D.G. MacKellar, Anal. Chem. 20, 1061 (1948).

15. D. Kubička, N. Kumar, P. Mäki-Arvela, M. Tiitta, V. Niemi, T. Salmi, D. Yu. Murzin, J.Catal. 222, 65 (2004). 
16. P. Mäki-Arvela, N. Kumar, V. Nieminen, R. Sjöholm, T. Salmi, D. Yu. Murzin, J.Catal. 225, 155 (2004).

17. E.M. Sulman, V.V. Alferov, Yu. Yu. Kosivtsov, A.I. Sidorov, O.S. Misnikov, A.E. Afanasiev, N. Kumar, D. Kubicka, J. Agullo, T. Salmi, D. Yu. Murzin, Chem. Eng. J. 134, 162 (2007).

18. A. Aho, N. Kumar, K. Eränen, T. Salmi, M. Hupa, D. Yu. Murzin, Fuel 87, 2493 (2008).

19. J.P. Marques, I. Gener, P. Ayrault, J.C. Bordado, J.M. Lopes, F.R. Ribeiro, M. Guisnet, C.R. Chimie 8, 399 (2005).

20.P.K. Sengupta, R.N. Tiwari, S. Bhagat, Chem. Eng. World 32, 89 (1997).

21. G.O. Rocha, R.A.W. Johnstone, B.F. Hemming, P.J.C Pires, J.P. Sankey, J. Mol. Catal. A: Chemical 186, 127 (2002).

22. A.E.W. Beers, J.A van Bokhoven, K.M. de Lathouder, F. Kapteijn, J.A. Moulijn, J. Catal. 218, 239 (2003).

23. D.M. Roberge, H. Hausmann, W.F. Hölderich, Phys. Chem. Chem. Phys. 4, 3128 (2002).

24. R.L. Hartman, H.S. Fogler, Ind. Eng. Chem. Res. 44, 7738 (2005).

25. J. De Laat, G. T. Le, B. Legube, Chemosphere 55, 715 (2004).

26. B. Mani, Ch. Ravi Mohan, V. Sitakara Rao, React. Kinet. Catal. Lett. 13, 277(1980).

27. W. Lutz, H. Toufar, R. Kurzhals, M. Suckow, Adsorption 11, 405 (2005).

28. M. Guisnet, F.R. Ribeiro, Les zéolithes, un nanomonde au service de la catalyse; EDP sciences (2006). 


\section{SCHEMES}

Scheme 1. Applications of $\mathrm{H}_{2} \mathrm{O}_{2}$ in fine chemical reactions

Scheme 2. Synthesis of PCA from the parent carboxylic acid and hydrogen peroxide

\section{FIGURES}

Fig. 1 Experiments carried out in the presence of $\mathrm{H}-\beta-25$ zeolite at $50^{\circ} \mathrm{C}$, at $350 \mathrm{rpm}$ and loading of $18.25 \mathrm{~g} / \mathrm{l}$

Fig. 2 Experiment carried out with a mixture of $\mathrm{PA}$ and $\mathrm{H}_{2} \mathrm{O}_{2}$ over alumina at $50^{\circ} \mathrm{C}$, at $350 \mathrm{rpm}$ and loading of $18.25 \mathrm{~g} / \mathrm{l}$

Fig. 3 Experiments carried out with a mixture of $\mathrm{PA}$ and $\mathrm{H}_{2} \mathrm{O}_{2}$ over $\mathrm{H}-\beta$ zeolites at $50^{\circ} \mathrm{C}$, at $350 \mathrm{rpm}$ and loading of $18.25 \mathrm{~g} / \mathrm{l}$

Fig. 4 Experiments carried out with a mixture of $\mathrm{PA}$ and $\mathrm{H}_{2} \mathrm{O}_{2}$ over $\mathrm{H}-\beta-75$ zeolites at $50^{\circ} \mathrm{C}$ and at $350 \mathrm{rpm}$

Fig. 5 Experiments carried out with a mixture of PA and $\mathrm{H} 2 \mathrm{O} 2$ over $\mathrm{H}-\mathrm{MCM}-41$ and $\mathrm{H}-\beta-75$ at $40^{\circ} \mathrm{C}$ and at $350 \mathrm{rpm}$

Fig. 6 Formation of PPA over different catalysts at $50^{\circ} \mathrm{C}$ at $43.38 \mathrm{~g} / \mathrm{l}$ of loading and $350 \mathrm{rpm}$

Fig. 7 Rate constants versus apparent $\left[\mathrm{H}^{+}\right]$

\section{TABLES}

Table 1. Channel structure of the tested aluminosilicate materials

Table 2. Experimental parameters for the catalyst comparison in the batch reactor Table 3. Properties of the aluminosilicate materials 
Table 4. Properties of Amberlite IR-120

Table 5. Apparent rate constants and $\left[\mathrm{H}^{+}\right]$ 


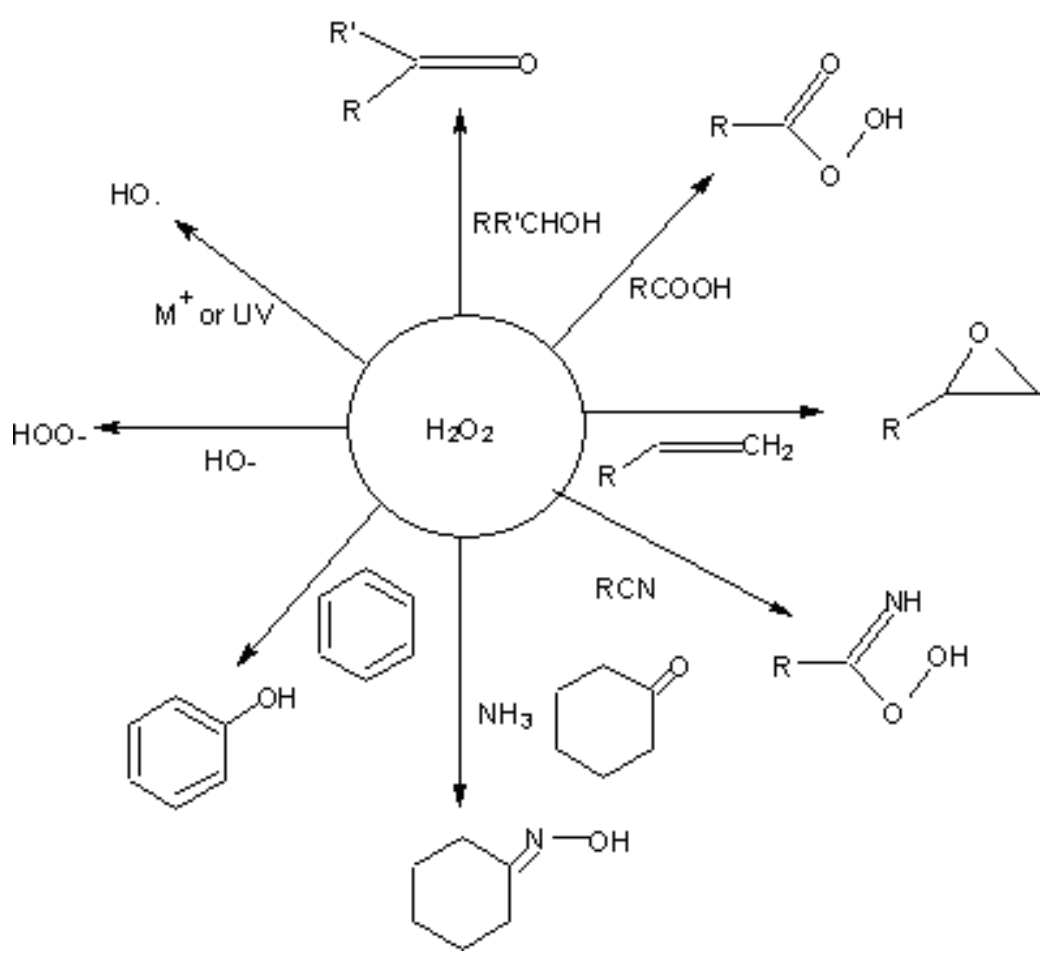

Scheme 1. Applications of $\mathrm{H}_{2} \mathrm{O}_{2}$ in fine chemical reactions 


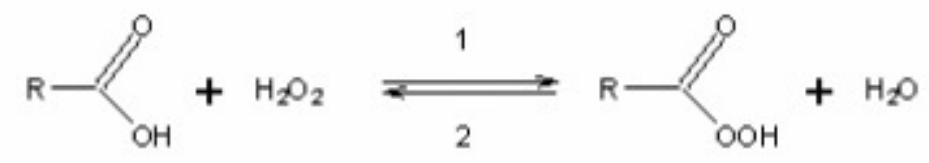

Scheme 2. Synthesis of PCA from the parent carboxylic acid and hydrogen peroxide 


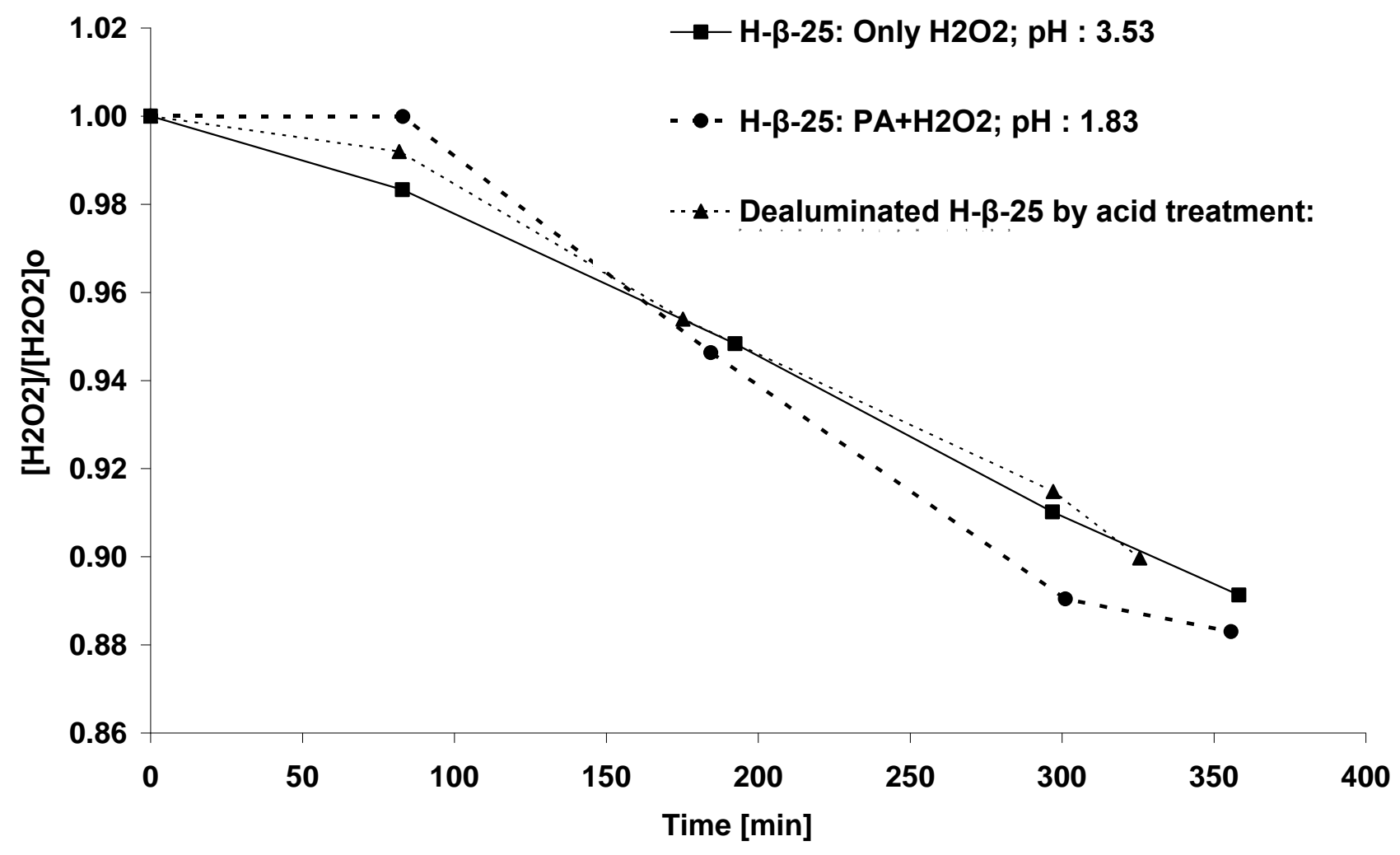

Fig. 1 Experiments carried out in the presence of $\mathrm{H}-\beta-25$ zeolite at $50^{\circ} \mathrm{C}$, at 350 rpm and loading of $18.25 \mathrm{~g} / \mathrm{l}$ 


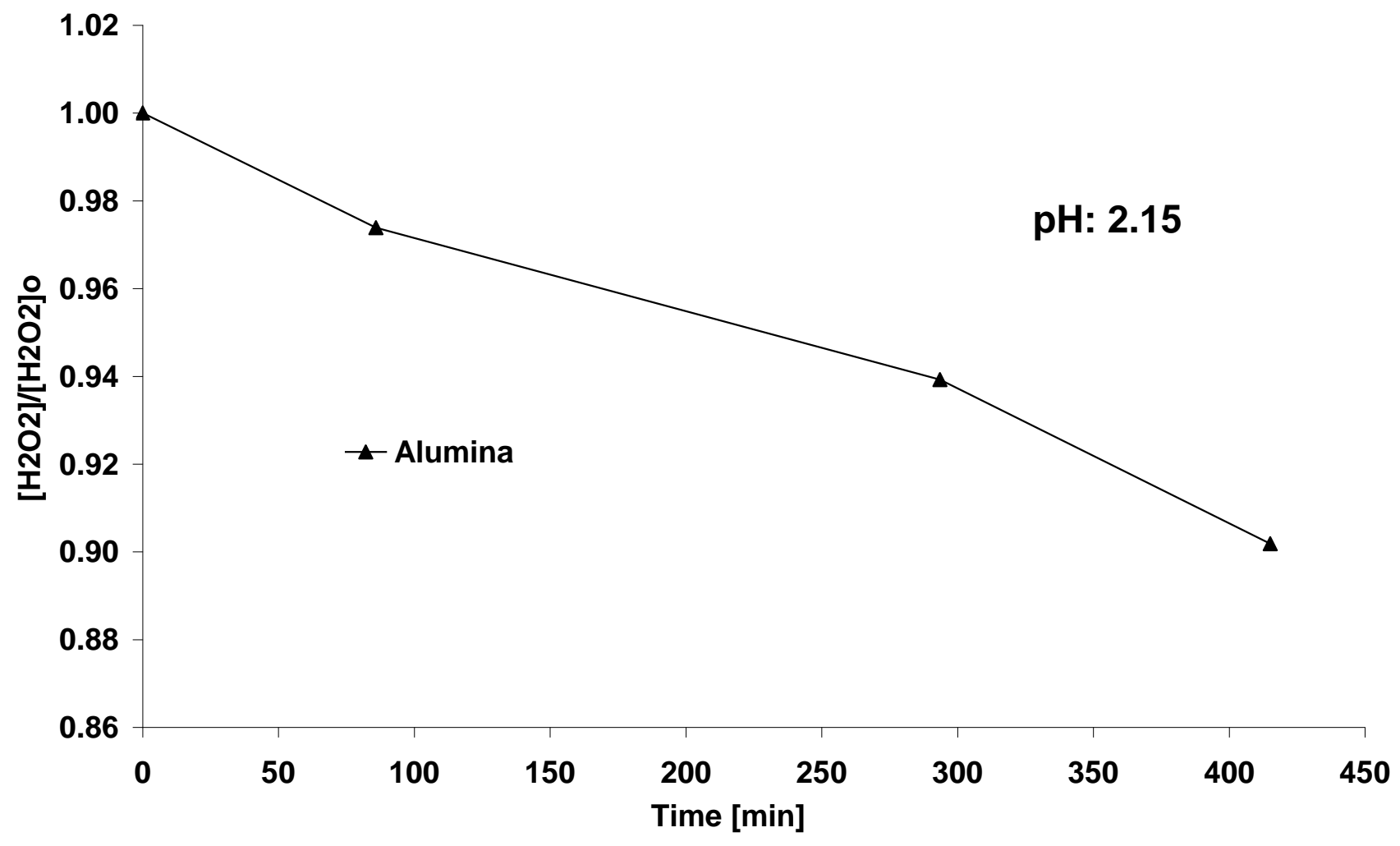

Fig. 2 Experiment carried out with a mixture of $\mathrm{PA}$ and $\mathrm{H}_{2} \mathrm{O}_{2}$ over alumina at $50^{\circ} \mathrm{C}$, at $350 \mathrm{rpm}$ and loading of $18.25 \mathrm{~g} / \mathrm{l}$ 


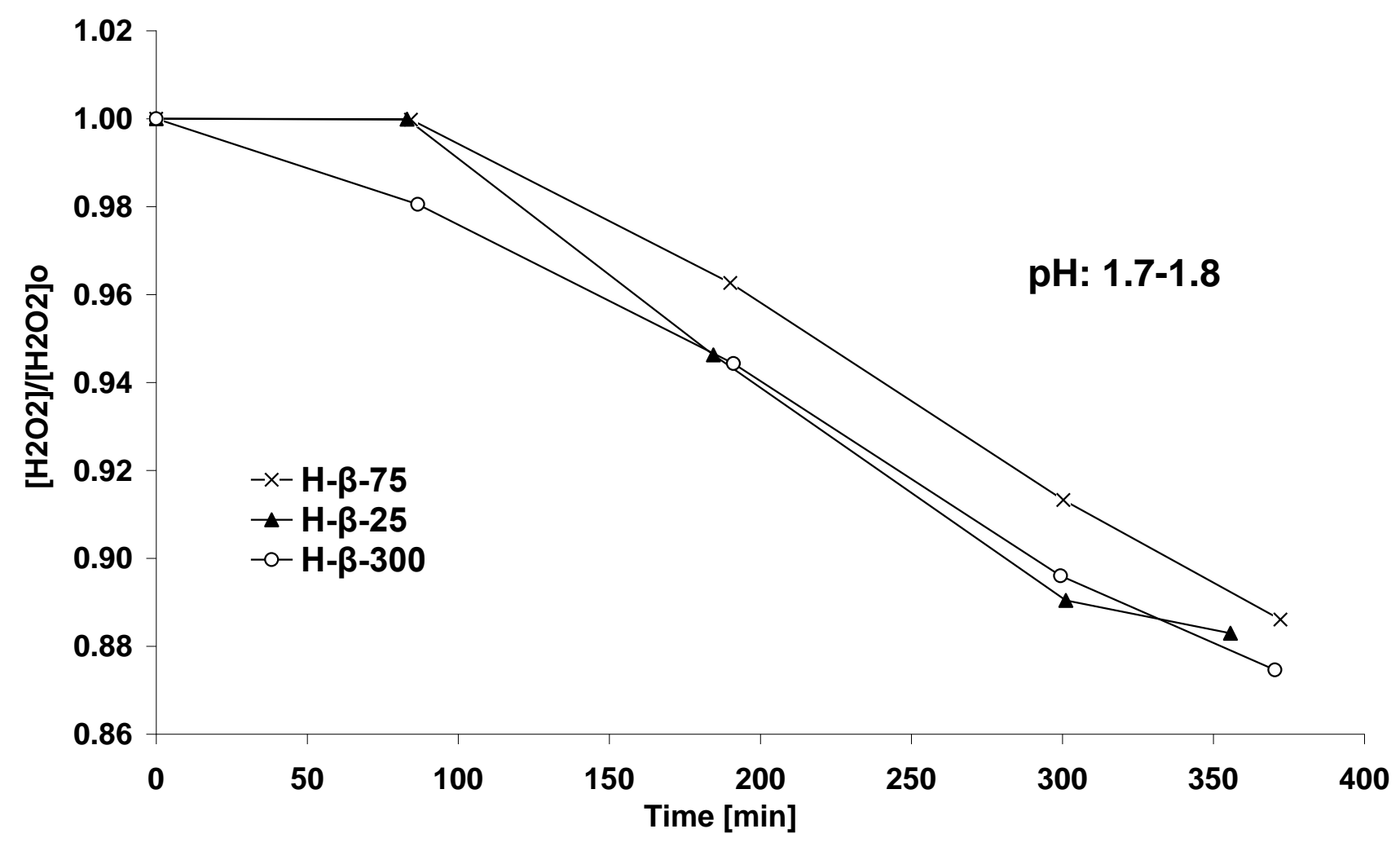

Fig. 3 Experiments carried out with a mixture of $\mathrm{PA}$ and $\mathrm{H}_{2} \mathrm{O}_{2}$ over $\mathrm{H}-\beta$ zeolites at $50^{\circ} \mathrm{C}$, at $350 \mathrm{rpm}$ and loading of $18.25 \mathrm{~g} / \mathrm{l}$ 


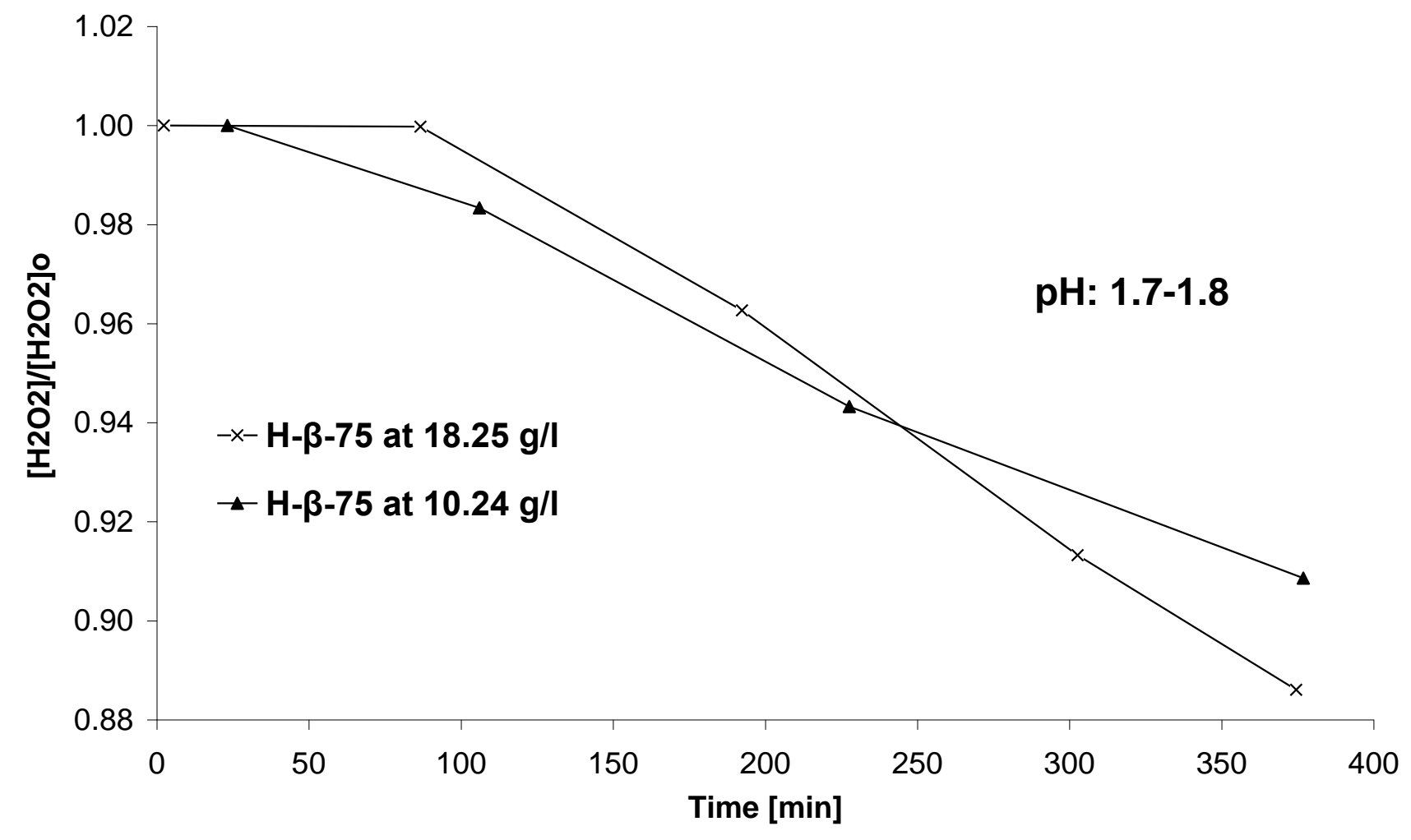

Fig. 4 Experiments carried out with a mixture of $\mathrm{PA}$ and $\mathrm{H}_{2} \mathrm{O}_{2}$ over $\mathrm{H}-\beta-75$ zeolites at $50^{\circ} \mathrm{C}$ and at $350 \mathrm{rpm}$ 


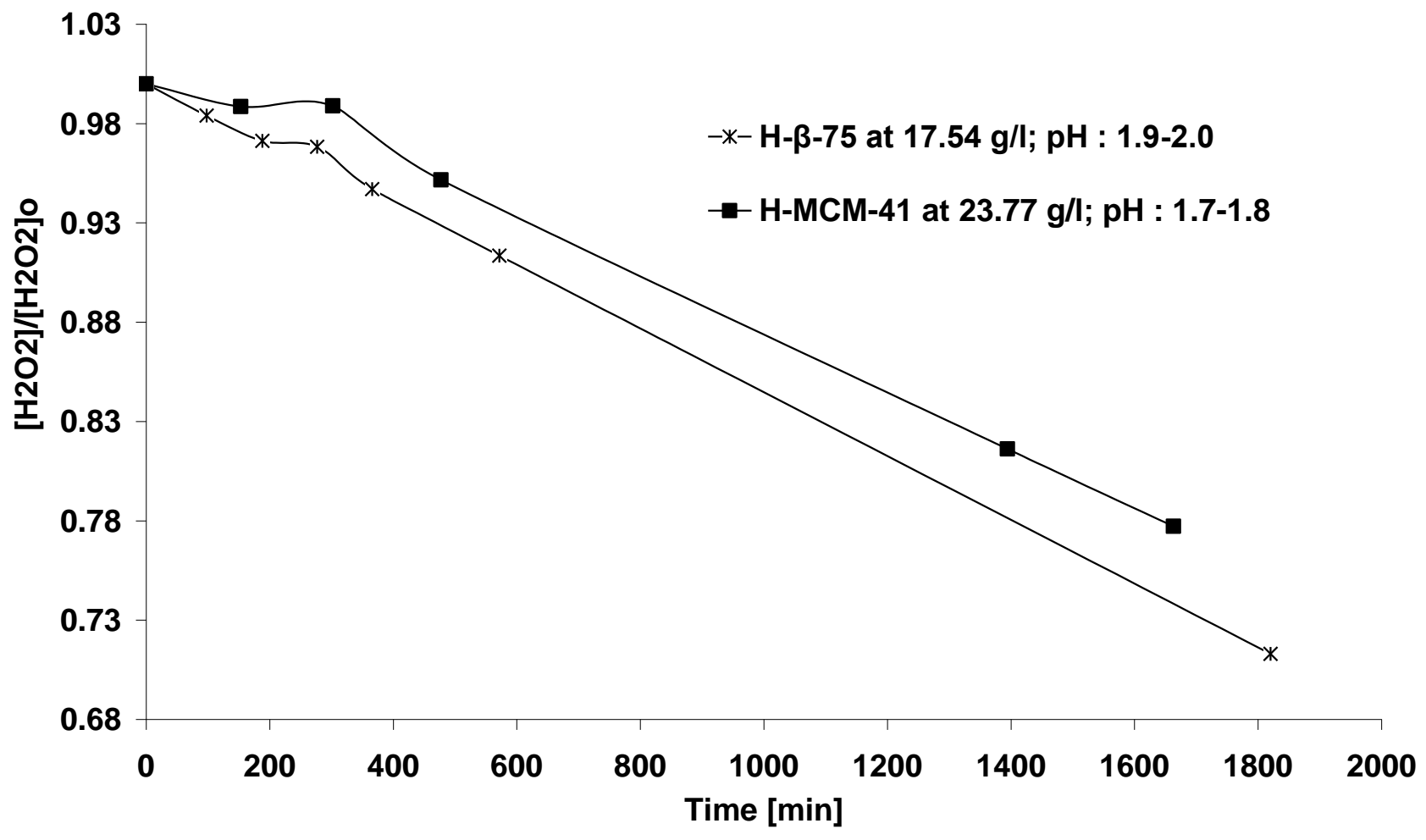

Fig. 5 Experiments carried out with a mixture of $\mathrm{PA}$ and $\mathrm{H}_{2} \mathrm{O}_{2}$ over $\mathrm{H}-\mathrm{MCM}-41$ and $\mathrm{H}-\beta-75$ at $40^{\circ} \mathrm{C}$ and at $350 \mathrm{rpm}$ 


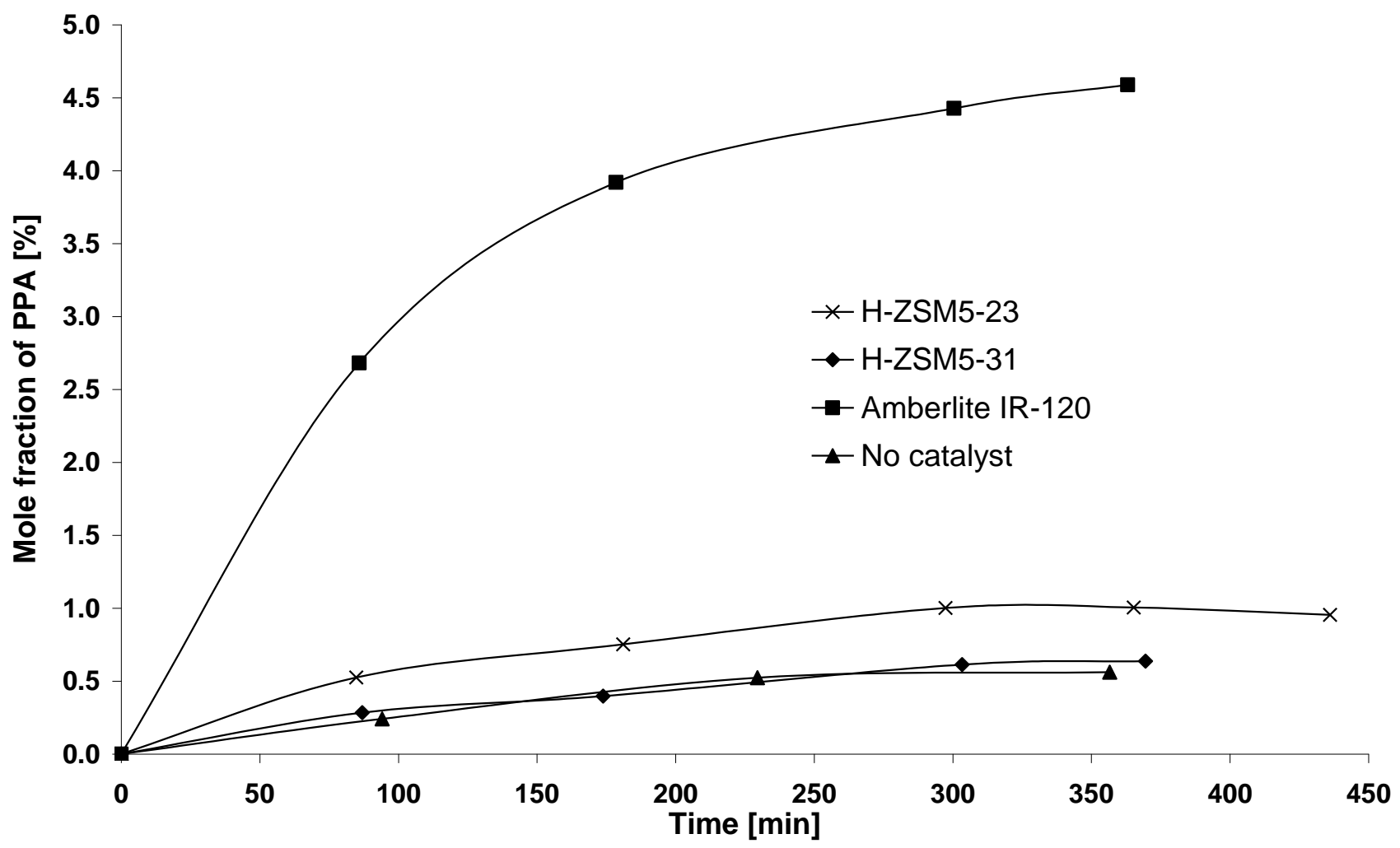

Fig. 6 Formation of PPA over different catalysts at $50^{\circ} \mathrm{C}$ at $43.38 \mathrm{~g} / \mathrm{l}$ of loading and $350 \mathrm{rpm}$ 


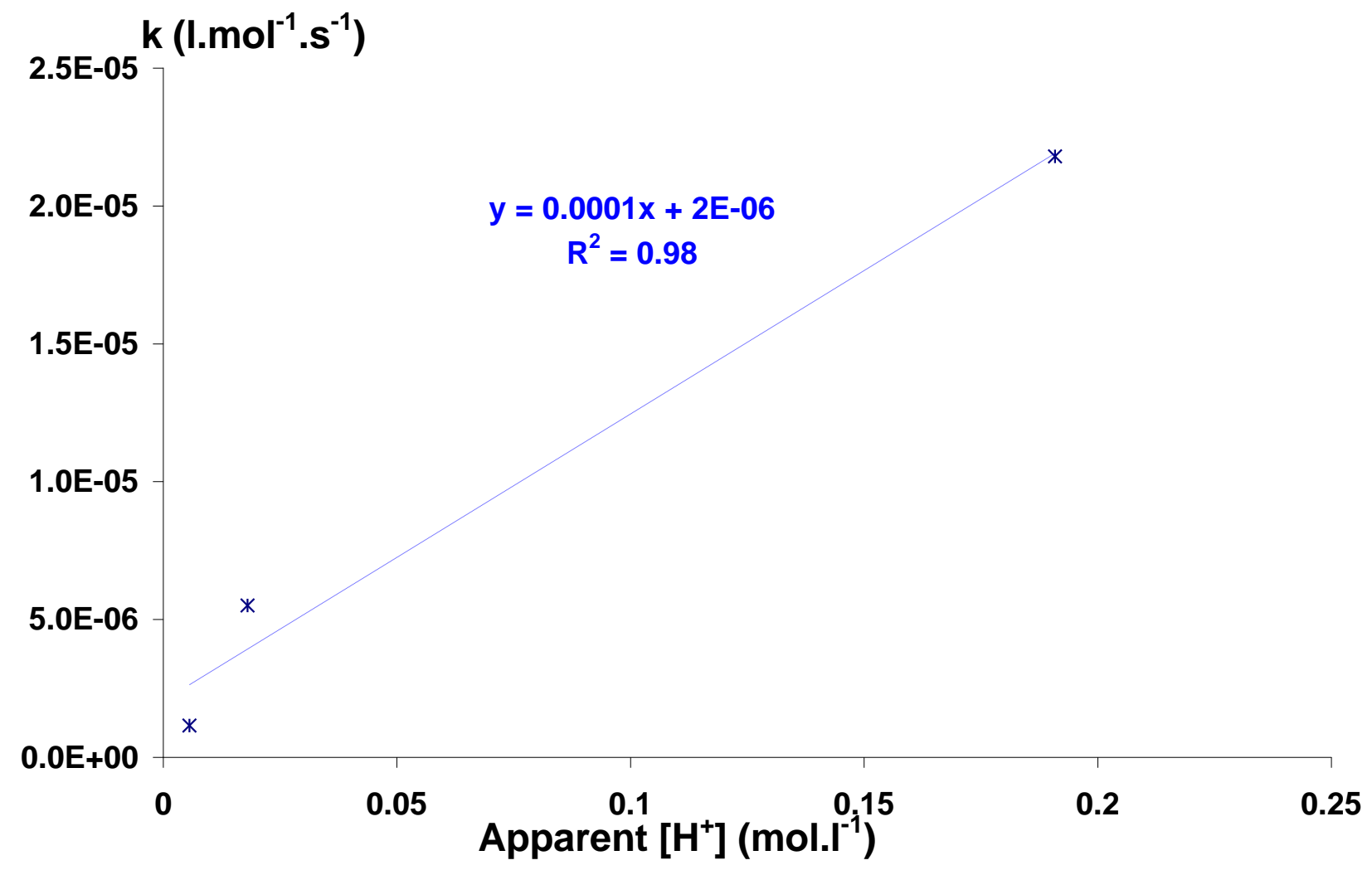

Fig. 7 Rate constants versus apparent $\left[\mathrm{H}^{+}\right]$ 
Table 1. Channel structure of the tested aluminosilicate materials

\begin{tabular}{|c|l|}
\hline Aluminosilicate materials & \multicolumn{1}{c|}{ Channel structure } \\
\hline$\beta$ & $\begin{array}{l}\text { 3-Dimensional pore system; 12-ring channel in c direction with pores } 7.6 \times \\
6.4 \AA \text { plus two 12-ring channels in a direction perpendicular to c-direction } \\
\text { with pores 7.6 } 6.4 \AA \text { and } 5.5 \times 5.5 \AA\end{array}$ \\
\hline ZSM-5 & $\begin{array}{l}\text { 3-Dimensional pore system; straight } 10 \text { member-ring } 5.2 \times 5.7 \AA \text { channels } \\
\text { connected by sinusoidal 5.3 } 5.6 \AA \text { channels. Intersection cavity: } 9 \AA\end{array}$ \\
\hline MCM-41 & $\begin{array}{l}1 \text {-Dimensional hexagonal arrangement of uniformly open channels from } \\
15 \text { to } 100 \AA\end{array}$ \\
\hline
\end{tabular}


Table 2. Experimental parameters for the catalyst comparison in the batch reactor

\begin{tabular}{|c|c|}
\hline Reaction temperature $\left[{ }^{\circ} \mathrm{C}\right]$ & $40-50$ \\
\hline Rotating speed $[\mathrm{rpm}]$ & $250-350$ \\
\hline $\mathrm{H}_{2} \mathrm{O}_{2}\left[\mathrm{~mol}^{-1}{ }^{-1}\right]$ & $5.75-6.10$ \\
\hline $\mathrm{PA}\left[\mathrm{mol.}{ }^{-1}\right]$ & $5.70-5.80$ \\
\hline $\mathrm{H}_{2} \mathrm{O}\left[\right.$ mol. $\left.^{-1}\right]$ & $23.85-24.10$ \\
\hline${\text { Catalysts loading }\left[\mathrm{g.I}^{-1}\right]}^{-}$ & $8.26-43.40$ \\
\hline
\end{tabular}


Table 3. Properties of the aluminosilicate materials

\begin{tabular}{|c|c|c|c|c|}
\hline & $\begin{array}{c}\mathrm{SiO}_{2} / \mathrm{Al}_{2} \mathrm{O}_{3} \\
\mathrm{~mol} / \mathrm{mol}\end{array}$ & $\begin{array}{c}\text { Brønsted acid sites at } 523 \mathrm{~K} \\
\mu \mathrm{mol} / \mathrm{g}\end{array}$ & Lewis acid sites at $523 \mathrm{~K}$ & $\begin{array}{c}\text { Specific surface area } \\
\mathrm{m}^{2} / \mathrm{g}\end{array}$ \\
\hline$H-\beta-25$ & 25 & 269 & 162 & 807 \\
\hline$H-\beta-75$ & 75 & 147 & 39 & 664 \\
\hline$H-\beta-300$ & 300 & 82 & 30 & 805 \\
\hline H-ZSM5-23 & 23 & 416 & 36 & 443 \\
\hline H-ZSM5-31 & 31 & - & - & - \\
\hline $\mathrm{Al}_{2} \mathrm{O}_{3}$ & - & 7 & 156 & 299 \\
\hline H-MCM-41 & 40 & 26 & 40 & 1242 \\
\hline
\end{tabular}


Table 4. Properties of Amberlite IR-120

\begin{tabular}{|c|c|}
\hline Supplier & Aldrich \\
\hline Polymer type & Gel \\
\hline $\begin{array}{c}\text { Cross linking } \\
\%\end{array}$ & 8 \\
\hline $\begin{array}{c}\text { Moisture content } \\
\% \text { mass }\end{array}$ & 45 \\
\hline $\begin{array}{c}\text { Capacity by dry weight } \\
\text { meq/g }\end{array}$ & 4.4 \\
\hline $\begin{array}{c}\text { Native particle size range } \\
\mathrm{mm}\end{array}$ & $0.3-1.2$ \\
\hline
\end{tabular}


Table 5. Apparent rate constants and $\left[\mathrm{H}^{+}\right]$

\begin{tabular}{|c|c|c|}
\hline & $\mathrm{k}\left(\mathrm{I} \cdot \mathrm{mol}^{-1} \cdot \mathrm{s}^{-1}\right)$ & Apparent $\left[\mathrm{H}^{+}\right]\left(\mathrm{mol}^{-1} \mathrm{I}^{-1}\right)$ \\
\hline H-ZSM-5-23 & $5.51 * 10^{-6}$ & $1.80^{*} 10^{-2}$ \\
\hline H-ZSM-5-31 & $2.95^{*} 10^{-6}$ & - \\
\hline Amberlite IR-120 & $2.18^{*} 10^{-5}$ & $1.91 * 10^{-1}$ \\
\hline Without catalyst & $1.15^{*} 10^{-6}$ & $5.64^{*} 10^{-3}$ \\
\hline
\end{tabular}

